\title{
Experimental Study and Finite Element Analysis of Critical Stresses of Reinforced Thermoplastic Pipes under Various Loads
}

\author{
G. H. Li, ${ }^{a, b}$ W. J. Wang, ${ }^{a, b, 1}$ Z. J. Jing, ${ }^{b}$ X. C. Ma, ${ }^{b}$ and L. B. Zuo ${ }^{a, b}$ \\ a Southwest Jiaotong University, Chengdu, China \\ ${ }^{\mathrm{b}}$ China Petroleum Pipeline Engineering Corp, Langfang, China \\ ${ }^{1}$ wwj_tumu@126.com
}

In this paper, reinforced thermoplastic pipes (RTP) were studied under various loads. A total of five groups of specimens were designed to study the mechanical properties of RTPS under internal pressure, bending, a combination of internal pressure and bending moment, external pressure, and tension. This study obtained the bursting pressure of RTPS under internal pressure, the minimum bending radius under the bending moment, and the failure pressure under external pressure. At the same time, the mechanical properties of RTPS under various loads were analyzed using the finite element analysis. Analytical results agree well with the experimental ones. The finite element model established in this paper can be used for further research on the mechanical properties of RTPS.

Keywords: reinforced thermoplastic pipe, internal pressure, bending, external pressure, tension.

Introduction. Pipes are widely used in urban and rural water supply, as well as oil and gas transportation industries. In the field of oil and gas pipelines, steel pipes are most widespread due to their high strength and good weldability. However, poor corrosion resistance, high quality defects, and the heavy self-weight of the whole steel pipe have restricted the development of oil and gas pipeline engineering. Although plastic pipes can provide a good corrosion resistance performance, their strength is too low to meet the requirements of oil and gas transportation. Fortunately, composite pipes overcome the shortcomings of steel and plastic ones and combine their advantages, which allows their rapid application in engineering. A reinforced thermoplastic pipe (RTP) is formed with an inner layer (polyethylene, etc.), a composite layer (polyester fiber, aramid fiber, highstrength steel wire), and an outer layer (polyethylene). The pipe structure is shown in Fig. 1. Such pipe exhibits high toughness and strength characteristics and is currently used for water transportation in marine, urban, and rural areas; it will be also promoted for long distance oil and gas pipelines.

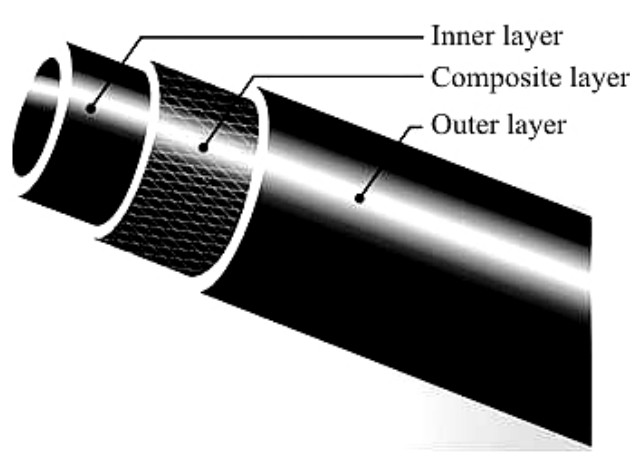

a

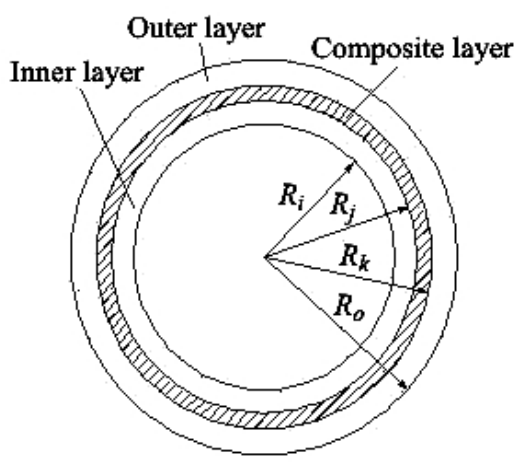

b

Fig. 1. The RTP structure (a) and sectional view (b). 
At present, scholars have been researching the mechanical response and strength of this kind of composite material. Some mechanical data, such as dependences between stresses, strains and displacements for composite pipes with different winding angles and thickness-to-diameter ratios under complex loads have been found [1-10]. The influence of the winding angle on the pipe critical load was also studied through experiments and finite element analysis [11-13]. However, RTPs will face more complex load conditions if they are used in long-distance oil pipelines. It is critical that the pipe can ensure the oil transportation safety. Therefore, more in-depth research on the mechanical properties of RTPs under various loads is necessary to provide a reference for the design of oil and gas pipelines. This paper focuses on the mechanical properties of RTPs reinforced with steel wire under various loads, such as internal pressure, bending, a combination of internal pressure and bending, external pressure, and tension, by experimental study and finite element analysis.

\section{Experimental.}

1.1. General Description of Test Procedures. Five groups of specimens with two specimens in each group are used to study the mechanical properties of RTPs. The length of RTPs under internal pressure is $900 \mathrm{~mm}$, under pure bending is $3300 \mathrm{~mm}$, for a combination of internal pressure and bending is $2000 \mathrm{~mm}$, under external pressure is $1000 \mathrm{~mm}$, and under tension is $1000 \mathrm{~mm}$. Table 1 shows the parameters of the specimens, where $R_{s t}$ is the wire radius and $\alpha$ is the steel wire-winding angle of reinforced layer (i.e., the angle between the wire winding direction and circumferential direction). Other parameters are depicted in Fig. 1. The strength of the steel wire is $2100 \mathrm{MPa}$, and the strength of the polyethylene (PE) is $25 \mathrm{MPa}$. The bending radius is $1 \mathrm{MBR}$ (minimum bending radius) for first specimen and $2 \mathrm{MBR}$ for second in the test of internal pressure and bending moment.

T a b 1 e 1

\section{RTP Parameters}

\begin{tabular}{|c|c|c|c|c|c||}
\hline$R_{i}, \mathrm{~mm}$ & $R_{j}, \mathrm{~mm}$ & $R_{k}, \mathrm{~mm}$ & $R_{o}, \mathrm{~mm}$ & $R_{s t}, \mathrm{~mm}$ & $\alpha, \mathrm{deg}$ \\
\hline 73 & 77 & 79.5 & 82.5 & 0.5 & 57 \\
\hline
\end{tabular}

1.2. Test Equipment and Loading Program. The bursting test was conducted via the internal pressure test based on the case of "Standard Test Method for Resistance to Short-Time Hydraulic Pressure of Plastic Pipe, Tubing and Fitting (ASTM D1599)." The test device is shown in Fig. 2. The pressure increased uniformly and continuously with a rate of $0.6 \mathrm{MPa} / \mathrm{s}$ until the specimen was damaged.

A simple beam device with a pure bending section was used in the bending test; it is illustrated in Fig. 3. The displacement-controlled loading was used with gradual displacement increase per a certain loading rate.

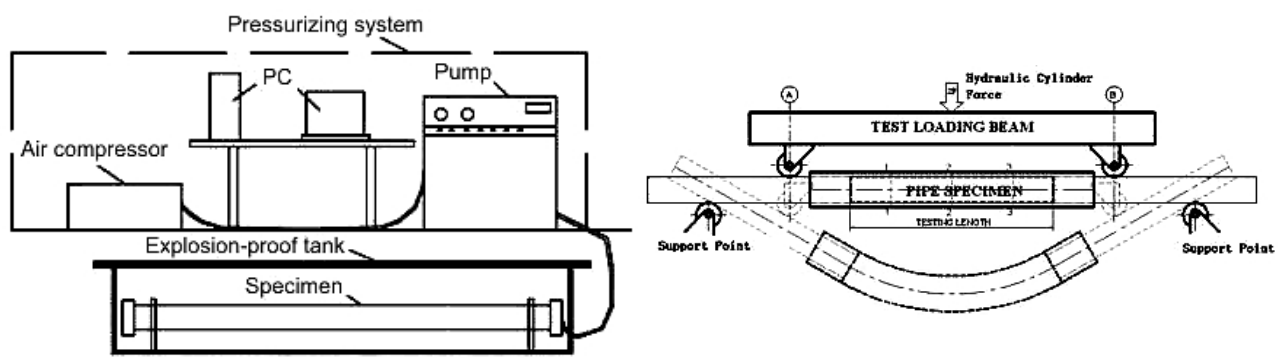

Fig. 2. Short-time bursting pressure test device.

Fig. 3. Pure bending loading device. 
The test device of the internal pressure and bending moment was the combination of the two, as shown in Fig. 4. When the specimen reached a certain bending radius, the pressure increased uniformly and continuously until the specimen was damaged.

Short-time static pressure test equipment was used in the external pressure test, as shown in Fig. 5. The pressure increased at a constant rate until the pipe failure, which occurred in 1-5 min due to the pipe buckling or compression failure.

The tensile test was carried out by an electromagnetic servo testing machine with a $6 \mathrm{~mm} / \mathrm{min}$ travel speed until the specimen failure. Figure 6 shows the testing device configuration.

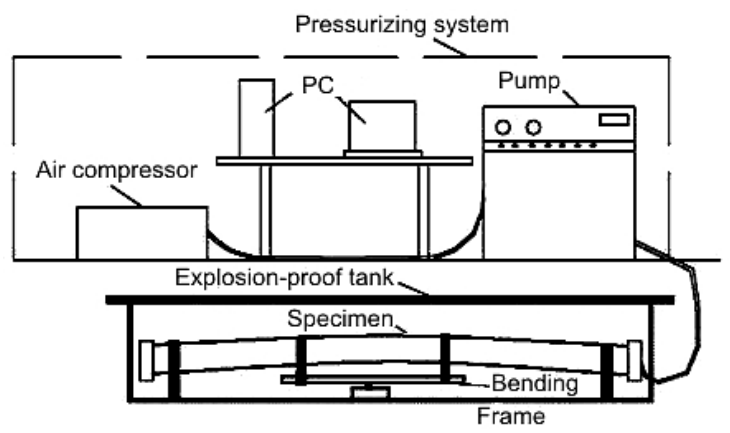

Fig. 4. The test device for combined loading of the internal pressure and bending moment.

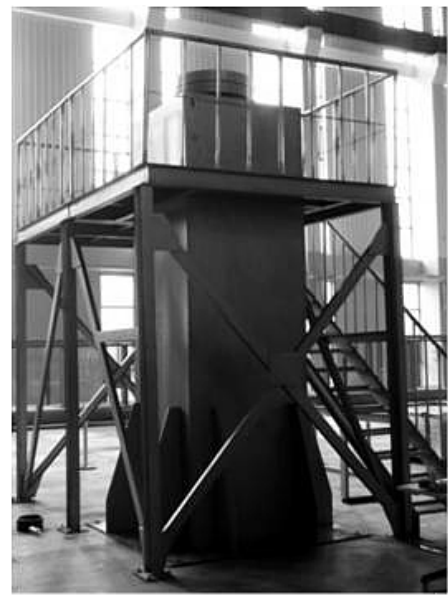

Fig. 5. Test device for the external pressure loading.

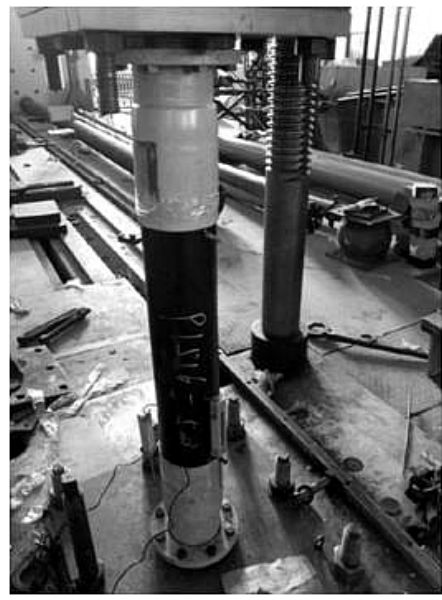

Fig. 6. Tensile test device.

\subsection{Test Results.}

1.3.1. Internal Pressure Test Results. Figure 7 shows the damages of specimens under internal pressure loads. Both bursting damages to the two specimens occurred near the end of the pipes. Figure 8 records the pressure variation with time; it shows that the pressure inside the specimens increased rapidly during the initial loading, and then the increase rate slowed down. The pressure suddenly dropped down close to 0 when the RTP burst occurred. The pressure curves of the two specimens are very similar, which indicates that the test device is stable and the test results are reliable. The ultimate burst pressures of the RTPs under internal pressure measured by the test are 18.79 and $18.86 \mathrm{MPa}$ for specimens $\# 1 \mathrm{~A}$ and \#2A, respectively.

1.3.2. Bending Test Results. In order to ensure that the specimens were subjected to pure bending conditions under the bending load, the pure bending section was set at the loading device, and a concentrated force was applied to the loading beam. The loading and 


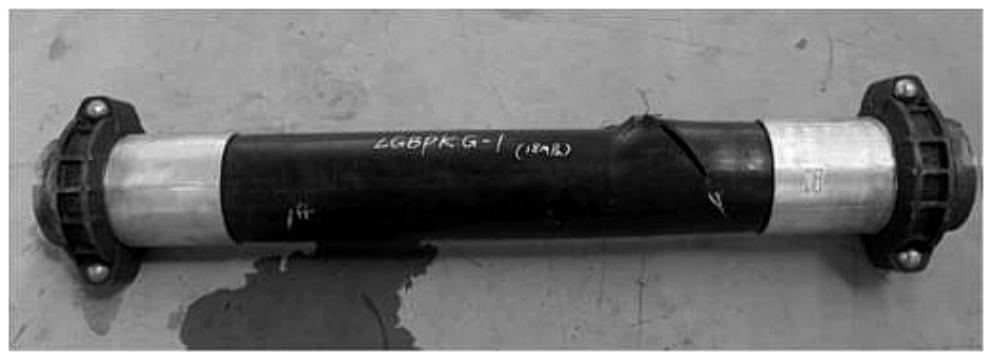

Fig. 7. Damages of specimens under the internal pressure loading conditions.

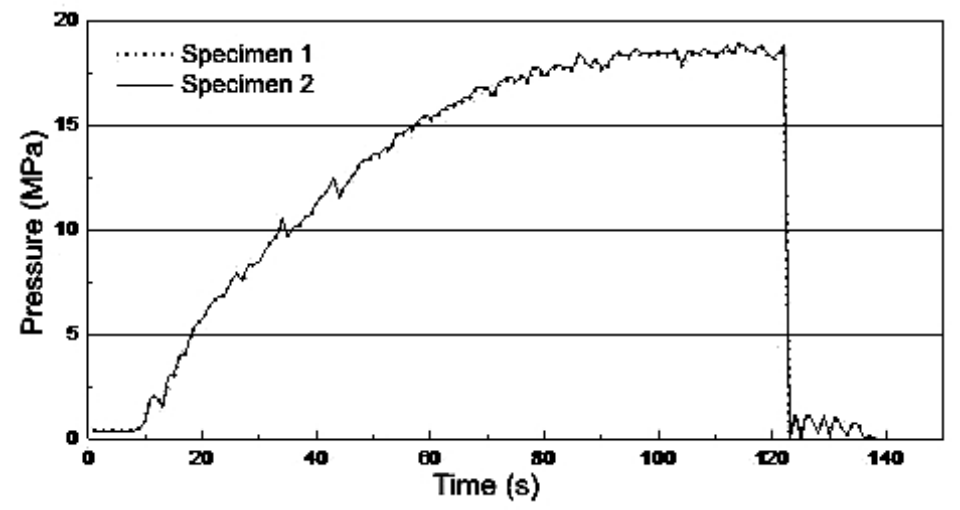

Fig. 8. Pressure curves under the internal pressure loading conditions.

failure conditions are depicted in Fig. 9. The RTP was concaved in the mid-span of the specimen when damage occurred. The load and displacement of the mid-span of the specimens were recorded in the test, and the load-displacement curves are shown in Fig. 10. The above curves of the two tested specimens are slightly different, but the basic pattern is consistent. At the early loading stage the load increased along with the displacement. Then the rate of increase gradually slowed at the middle stage until it reached its maximum load. At the final loading stage the load in the mid-span declined with the increase of displacement, and the specimen was damaged. The loading curves are different from those obtained under internal pressure. The load had a slow decline without a sudden drop. The minimum bending radius of specimens $\# 1 \mathrm{~B}$ and \#2B measured in the test were 1.36 and $1.42 \mathrm{~m}$, respectively.

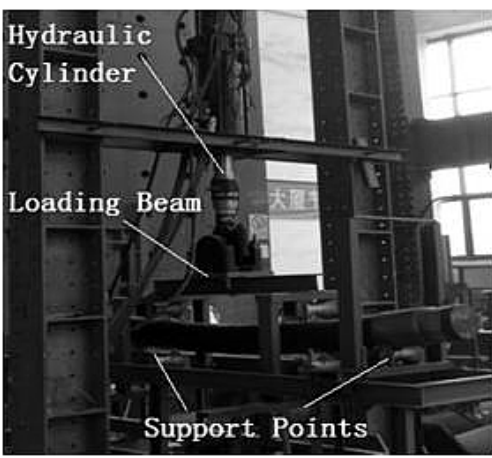

a

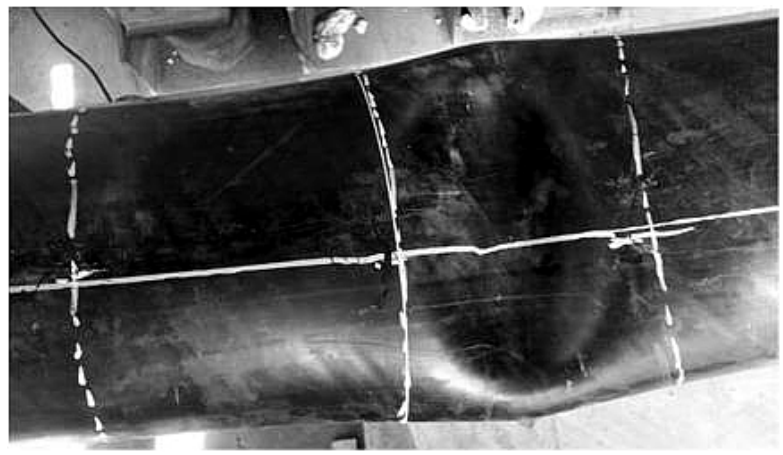

b

Fig. 9. Loading configuration (a) and specimen damage (b) under bending test conditions. 


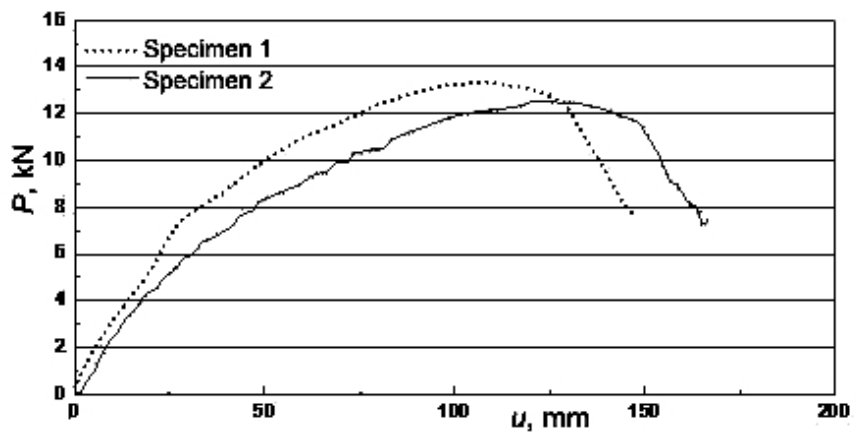

Fig. 10. Load-displacement curves of bending test.

1.3.3. Combination of Internal Pressure and Bending Moment. The internal pressure and bending moment were combined by means of applying the internal pressure after the RTPs reached a certain curvature by a constant bending moment. Figure 11 shows the bursting damages near the center of the specimen. Figure 12 shows that the pressure curves derived from the tests are different, whereas the bending radius of specimen $\# 1 \mathrm{C}$ is $1 \mathrm{MBR}$, and that of specimen $\# 2 \mathrm{C}$ is $2 \mathrm{MBR}$. As compared with the pressure curve under the pure internal pressure condition, the curve shape for the specimen with a 1 MBR bending radius was similar, while for the specimen with a 2 MBR bending radius, the pressure did not increase obviously for quite a long time at the early stage, which was quite different. On the contrary, it climbed dramatically in the middle period to the highest point, and then burst out and made a sudden drop. No gradual climbing stage was observed before the maximum value was reached. This proves that the damages from interval pressure to the specimen with a 2 MBR bending radius were more abrupt. The ultimate bursting pressures for specimens \#1C and \# 2C acquired from this test were 16.1 and $19.1 \mathrm{MPa}$, respectively.

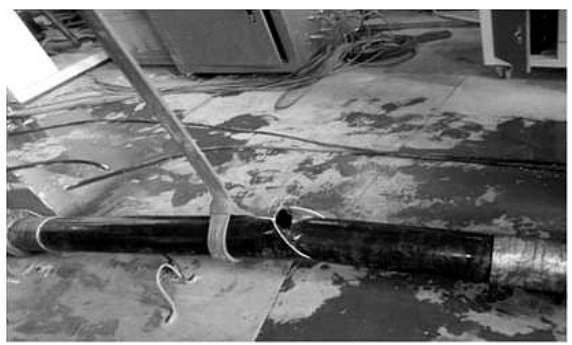

Fig. 11. Specimen damage under the combination of internal pressure and bending moment.

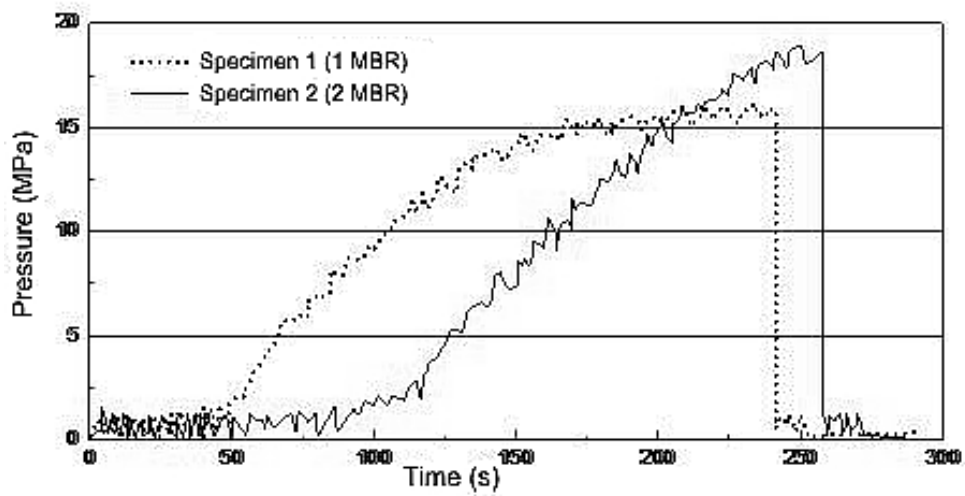

Fig. 12. Pressure curve under the combination of internal pressure and bending moment. 
1.3.4. External Pressure Test Results. Figure 13 shows the damages the specimens received under external pressure. Invagination occurred near the center of the pipe. Figure 14 illustrates that the shapes of the pressure curves for the two specimens under external pressure were nearly the same. Unlike under the condition of internal pressure, the pressure of the RTPs increased drastically to the maximum value as soon as the pipe began to withstand the external pressure. The increasing rates during the whole rising phase were nearly the same. After the RTPs were damaged, the pressure declined rapidly to nearly $50 \%$ of its maximum value and then stopped declining and remained unchanged. The maximum pressures acquired in this test for specimens \#1D and \#2D were 0.565 and $0.524 \mathrm{MPa}$, respectively.

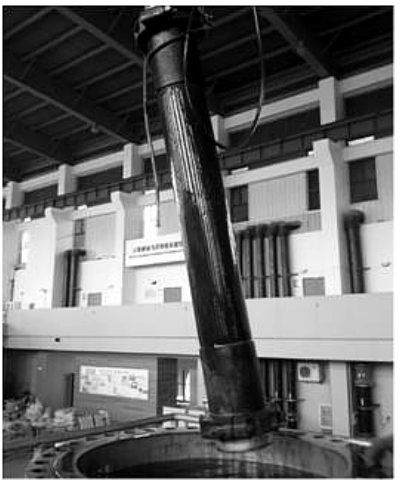

Fig. 13

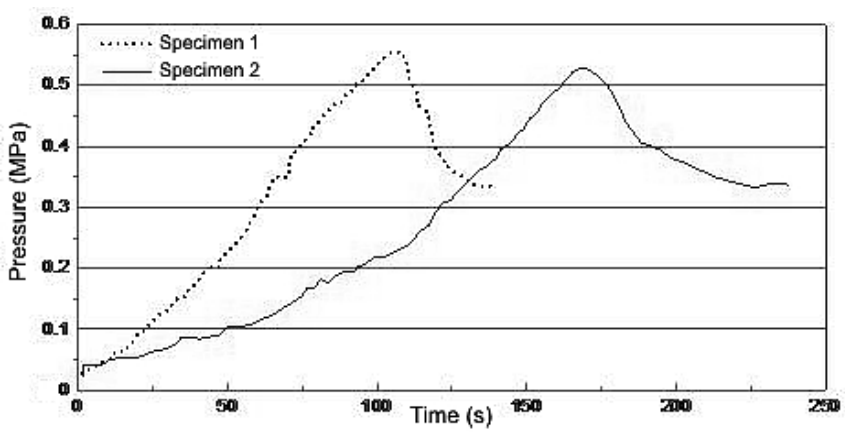

Fig. 14

Fig. 13. Damage under external pressure.

Fig. 14. Pressure curve under external pressure.

1.3.5. Tensile Test Results. To obtain the tensile properties of RTPs, a servo-testing machine was adopted to carry out a tensile test with a constant tensile loading rate. Damages to the specimens are recorded in Fig. 15, which proves that the necking phenomenon was obvious when the RTPs were damaged by tension. Figure 16 shows the tensile load-displacement curves acquired from the test, which were nearly the same at the initial loading stage, but exhibited a big difference when the necking occurred. The tensile force values measured prior to necking are 100.2 and $104 \mathrm{kN}$ for specimens \#1E and \#2E, respectively.

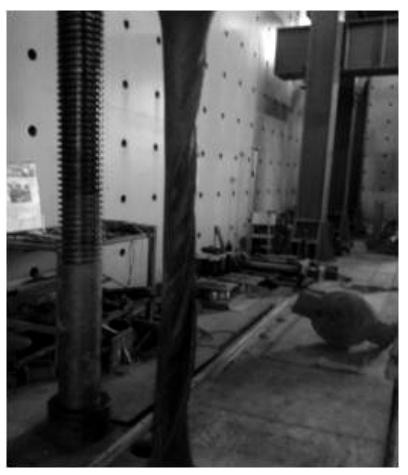

Fig. 15

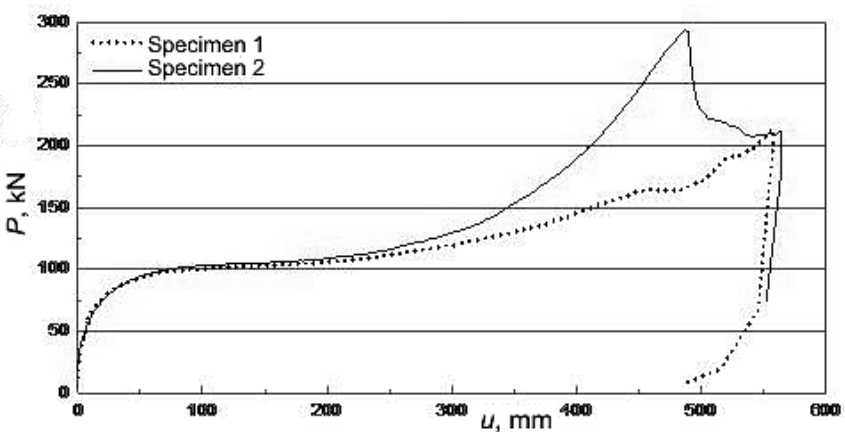

Fig. 16

Fig. 15. Specimen damages under tensile loading conditions.

Fig. 16. Tensile load-displacement curve of specimens. 


\section{Finite Element Analysis.}

2.1. Basic Assumptions. The finite element method is widely used in various analyses $[14,15]$. The finite element software ABAQUS was adopted to simulate the mechanical properties of RTPs in different conditions. For ease of calculation, it was assumed that the steel wires and polythene were strained continuously at the interface without relative sliding while establishing the finite element model. Both the steel wire and polythene were in the condition of small-scale deformation, linear elasticity, and no initial stress. The weight of the RTPs was disregarded in the calculations.

2.2. Geometric Parameters of Models and Properties of Materials. The geometric parameters of the finite element model used in this study are taken form the test. The mechanical properties of the materials are tabulated in Table 2.

T a b 1 e 2

Mechanical Properties of Pipe Materials

\begin{tabular}{|c|c|c|c|c|c||}
\hline \hline Material & $\begin{array}{c}\text { Density } \\
\left(\mathrm{kg} / \mathrm{m}^{3}\right)\end{array}$ & $\begin{array}{c}\text { Elastic } \\
\text { modulus } \\
(\mathrm{MPa})\end{array}$ & $\begin{array}{c}\text { Poisson's } \\
\text { ratio }\end{array}$ & $\begin{array}{c}\text { Ultimate } \\
\text { tensile } \\
\text { strength } \\
(\mathrm{MPa})\end{array}$ & $\begin{array}{c}\text { Ultimate } \\
\text { compressive } \\
\text { strength } \\
(\mathrm{MPa})\end{array}$ \\
\hline Polythene & 940 & 1002 & 0.45 & 26.5 & 25 \\
\hline Steel wire & 7800 & 210000 & 0.26 & 2100 & - \\
\hline
\end{tabular}

2.3. Finite Element Model. The C3D8R unit of ABAQUS was selected to simulate the RTP polythene material, because it can calculate with high accuracy and high speed. The dual node 3D Truss unit was used to simulate the steel wires embedded in the pipes, because, as with steel wire, the unit considers only the axial direction force, but not the bearing bending moment. The finite element model is shown in Fig. 17.

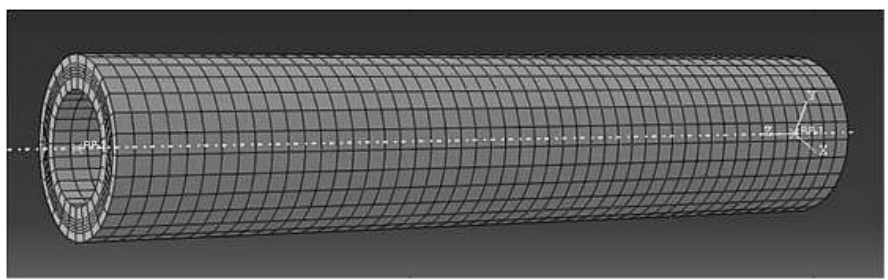

a

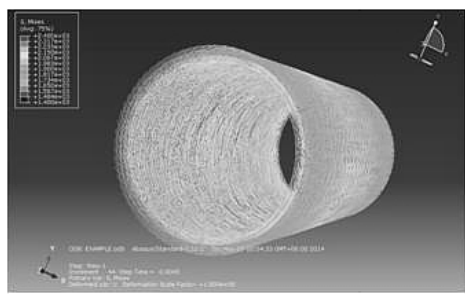

b

Fig. 17. Finite element model mesh for RTP (a) and calculated stresses in the steel wire (b) under internal pressure conditions.

2.4. Calculated Results. As in the experimental study, five different calculation results were derived by applying loads to the finite element model under five different conditions: internal pressure, bending, a combination of external pressure and bending moment, 
external pressure, and tension. Figure 18 depicts stresses in the steel wire stresses and the outer polythene layer of the RTPs, which implies that the stresses calculated by the finite element model basically coincide with the experimental ones. To assess the accuracy of the analysis, a comparison between the calculated and test results is made in Table 3, which confirms their strong correlation, most of the deviations being within $10 \%$. This means that the finite element model used in this paper can be used to simulate the mechanical properties of RTPs under different loads.

$\mathrm{T}$ a b 1 e 3

\section{Comparison of Finite Element Analysis and Test Results}

\begin{tabular}{|c|c|c|c|c|c|c|c|c|c|c|}
\hline \multirow{2}{*}{\begin{tabular}{c|} 
Condition \\
\\
$\begin{array}{c}\text { Specimen } \\
\text { number }\end{array}$ \\
\end{tabular}} & \multicolumn{2}{|c|}{$\begin{array}{c}\text { Bursting } \\
\text { pressure } \\
\text { under } \\
\text { internal } \\
\text { pressure } \\
(\mathrm{MPa})\end{array}$} & \multicolumn{2}{|c|}{$\begin{array}{l}\text { Minimum } \\
\text { bending } \\
\text { radius } \\
\text { under } \\
\text { bending } \\
\text { (m) }\end{array}$} & \multicolumn{2}{|c|}{$\begin{array}{l}\text { Bursting pressure } \\
\text { for a combination } \\
\text { of internal pressure } \\
\text { and bending } \\
\text { moment }(\mathrm{MPa})\end{array}$} & \multicolumn{2}{|c|}{$\begin{array}{c}\text { Failure } \\
\text { pressure } \\
\text { under } \\
\text { external } \\
\text { pressure } \\
(\mathrm{MPa})\end{array}$} & \multicolumn{2}{|c|}{$\begin{array}{c}\text { Necking } \\
\text { tensile } \\
\text { load } \\
(\mathrm{kN})\end{array}$} \\
\hline & $\# 1 \mathrm{~A}$ & $\# 2 \mathrm{~A}$ & $\# 1 \mathrm{~B}$ & $\# 2 \mathrm{~B}$ & $\# 1 \mathrm{C}$ & $\# 2 \mathrm{C}$ & $\# 1 \mathrm{D}$ & $\# 2 \mathrm{D}$ & $\# 1 \mathrm{E}$ & $\# 2 \mathrm{E}$ \\
\hline $\begin{array}{l}\text { Experimental } \\
\text { value }\end{array}$ & 18.79 & 18.86 & 1.360 & 1.420 & 16.1 & 19.10 & 0.565 & 0.524 & 100.2 & 104.0 \\
\hline $\begin{array}{l}\text { Analysis } \\
\text { value }\end{array}$ & 20.88 & 20.88 & 1.346 & 1.346 & 17.7 & 18.17 & 0.580 & 0.580 & 104.3 & 104.3 \\
\hline Deviation $(\%)$ & 11.12 & 10.71 & 1.03 & 5.21 & 9.94 & 4.87 & 2.65 & 10.69 & 4.09 & 0.29 \\
\hline
\end{tabular}

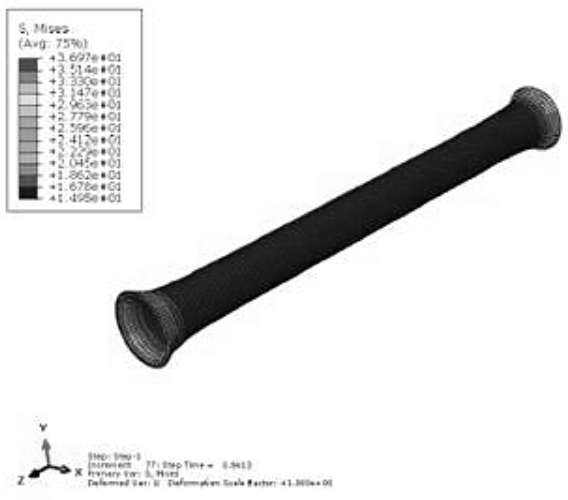

a

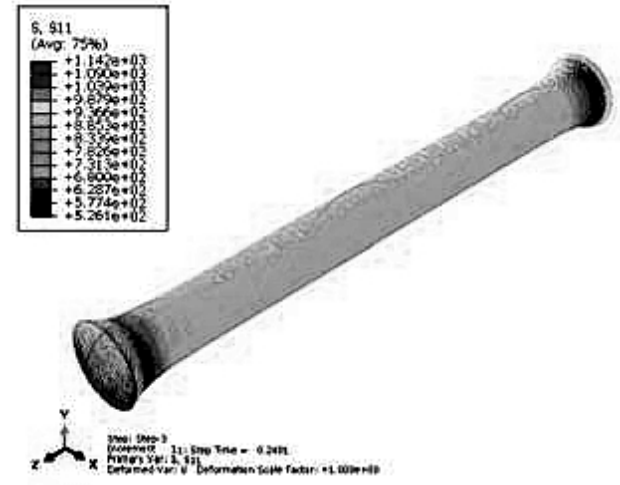

b

Fig. 18. Calculated stresses in the RTP outer layer (a) and steel wire (b) under tensile loading conditions.

Conclusions. On the basis of the above study on the mechanical properties of RTPs under various loads by tests and finite element simulations, the following conclusions are drawn:

1. Burst occurs to a pipe when the bursting pressure of the RTP under internal pressure is above $18 \mathrm{MPa}$, whereas invagination occurs at the middle section of a pipe when the minimum bending radius of the RTP under bending is above $1 \mathrm{~m}$. The RTP bursting pressure under a combination of internal pressure and bending moment is the same as that under the conditions of pure internal pressure; however, the burst of the RTP is more abrupt when the bending moment attains higher values. 
2. Invagination occurs at the pipe middle section when the failure pressure of the RTP under external pressure is above $0.5 \mathrm{MPa}$. Unlike when the RTP is subjected to the internal pressure, the pressure of the RTP declines rapidly when it is damaged by the external pressure, and this decline is steady until it approaches $50 \%$ of its maximum value. Necking occurs in the RTP under tension when the tensile force value is above $100 \mathrm{kN}$.

3. A strong correlation between the calculated and experimental damage conditions of the RTPs is observed. The finite element model proposed in this paper is shown to be applicable for assessment of the mechanical properties of RTPs under different types of loads.

1. M. Xia, H. Takayanagi, and K. Kemmochi, "Analysis of multi-layered filamentwound composite pipes under internal pressure," Compos. Struct., 53, 483-491 (2001).

2. M. Xia, H. Takayanagi, and K. Kemmochi, "Bending behavior of filament-wound fiber-reinforced sandwich pipes," Compos. Struct., 56, 201-210 (2002).

3. C. S. Chouchaoui and O. O. Ochoa, "Similitude study for a laminated cylindrical tube under tensile, torsion, bending, internal and external pressure. Part I: Governing equations," Compos. Struct., 44, 221-229 (1999).

4. C. S. Chouchaoui and O. O. Ochoa, "Similitude study for a laminated cylindrical tube under tensile, torsion, bending, internal and external pressure. Part II: Scale models," Compos. Struct., 44, 231-236 (1999).

5. J. Q. Tarn and Y. M. Wang, "Laminated composite tubes under extension, torsion, bending, shearing and pressuring: a state space approach," Int. J. Solids Struct., 38, 9053-9075 (2011).

6. A. L. Newberry, "Advanced software for stress analysis of composite pipe systems," Reinforced Plastics, 46, No. 10, 46-48 (2002).

7. Y. Zhang, X. M. Fan, and D. Kong, "Study on the mechanics model of multi-layered tube," J. Nanjing Univ. Sci. Technol., 23, No. 5, 446-449 (1999).

8. Zh. M. Ren, D. Y. Ren, K. L. Liu, and J. T. Liu, "The finite element analysis of steel wir frame reinforced plastic pipes," China Plastics, 16, No. 11, 40-43 (2002).

9. X. P. Cheng, Analysis and Study on Properties of Steel Framed Polyethylene Plastic Pipes, Master's Thesis, Zhejiang University, Hangzhou (2003).

10. W. Z. Yang, G. Q. Yang, and c. Yang, "Mechanics analysis on swaging process of hose assembly," Process Equip. Piping, 41, No. 2, 60-62 (2004).

11. C. A. GargiuIo, M. A. Marchetti, and A. A. Rizzo, "Prediction of failure envelopes of composite tubes subjected to biaxial loadings," Acta Astronaut., 39, No. 5, 355-368 (1996).

12. Y. W. Yang, Y. Zhen, and G. Sh. Qiu, "Stress analysis and strength check of FRP/PVC composite pipe," J. Nanjing Univ. Sci. Technol., 19, No. 4, 381-384 (1995).

13. Y. E. Zhang, X. M. Fan, and D. Kong, "Theoretical calculation of strength of multi-layered cylinder," J. Ballistics, 14, No. 1, 54-57 (2002).

14. T. Nitulescu and S. Talu, Applications of Descriptive Geometry and Computer Aided Design in Engineering Graphics, Risoprint Publishing House, Cluj-Napoca, Romania (2001), ISBN 973-656-102-X.

15. S. Talu and C. Racocea, Axonometric Representations with Applications in Technique, MEGA Publishing House, Cluj-Napoca, Romania (2007), ISBN 978-973-7867-98-8. 